\title{
Molecular tectonics: design of 2-D networks by simultaneous use of charge-assisted hydrogen and coordination bonds
}

\author{
Cristina Carpanese, ${ }^{a}$ Sylvie Ferlay, ${ }^{\text {a }}$ Nathalie Kyritsakas ${ }^{a}$ Marc Henry ${ }^{b}$ and Mir Wais Hosseini ${ }^{* a}$,
}

\author{
${ }_{5}$ Received (in XXX, XXX) Xth XXXXXXXXX 200X, Accepted Xth XXXXXXXXX 200X \\ First published on the web Xth $X X X X X X X X X 200 X$ \\ DOI: $10.1039 / \mathbf{b 0 0 0 0 0 0 x}$
}

Using a combination of charge-assisted $\mathrm{H}$ - and coordinationbonds, a tetra components system composed of a dicationic, a 10 dianionic organic tectons, $\mathrm{Ag}^{+}$cation and $\mathrm{XF}_{6}^{-}(\mathrm{X}=\mathbf{P}, \mathrm{As}, \mathrm{Sb})$ anion behaves as planned and leads to the formation of 2-D isostructural networks for which the energetic contributions of the two recognition events dominate the construction process.

In the area of crystal engineering ${ }^{1}$ predicting the crystal 15 structure is an important issue. ${ }^{2}$ This is less the case for the molecular tectonics approach ${ }^{3}$, which deals with the formation of molecular networks ${ }^{4}$ in the crystalline phase. Indeed, for this approach, the design of tectons and the prediction of connectivity patterns between them are the main points of

20 concern. ${ }^{5}$ For molecular tectonics, another issue is the number of tectons composing the system and the nature of the recognition patterns. ${ }^{6}$ As one may expect, the increase in the number of components is a challenging task since, in principle, it leads to a larger possibility space. ${ }^{4 b}$ Dealing with 25 the nature of the recognition pattern, the majority of described architectures are solely based on van der Waals contacts, ${ }^{7} \mathrm{H}$ bonds $^{8}$ or even more often on coordination processes. ${ }^{9}$ However few examples of combinations of the latter two types of interaction have been also reported. ${ }^{10}$

${ }_{30}$ Here we report on a four components system, combining both coordination events and charge-assisted H-bonding as assembling nodes, which behaves in terms of connectivity as planned.

The system (Fig. 1), is composed of $\mathbf{1}^{2+}$ as a dicationic $\mathrm{H}$ 35 bond donor tecton, $\mathbf{2}^{2-}$ as a dianionic $\mathrm{H}$-bond acceptor and as a coordinating tecton, $\mathrm{Ag}^{+}$as a connecting metal capable of being coordinated by $2^{2-}$ and finally, for charge balance, $\mathrm{XF}_{6}{ }^{-}$ $(\mathrm{X}=\mathrm{P}, \mathrm{As}, \mathrm{Sb})$ as a weakly coordinating monoanion.

Compound $\mathbf{1}^{2+}$ (Fig. 1) is a dicationic tecton bearing four 40 divergently oriented acidic protons. ${ }^{11 \mathrm{a}}$ The latter are distributed in two sets of two H-bond donor sites occupying the two faces of the tecton. Because of the length of the spacer (ethylene) connecting the two cyclic amidinium units, tecton $\mathbf{1}^{2+}$ recognises on each of its faces a carboxylate anion through 45 both electrostatic interactions and a dihapto mode of $\mathrm{H}$ bonding $^{12}$ (charge-assisted H-bonding ${ }^{13}$ ). Thus, $\mathbf{1}^{2+}$ may be regarded as a "double face scotch tape" connecting two carboxylate moieties (Fig. 1a). We have previously exploited this feature by generating varieties of charge assisted $\mathrm{H}$ ${ }_{50}$ bonded networks in the crystalline phase by combining the $\mathbf{1}^{2+}$ with dicarboxylate dianions. ${ }^{12}$ In particular, tecton $\mathbf{1}^{2+}$ leads in the presence of iso-phthalate ${ }^{11 \mathrm{~b}}$ and 3,5-pyridine dicarboxylate ${ }^{11 \mathrm{c}}$ to the formation of 1-D zigzag type neutral networks. Compound $\mathbf{2}^{2-}$ is a mixed tecton bearing two 55 carboxylate units as $\mathrm{H}$-bond acceptors which, in the presence of tecton $\mathbf{1}^{2+}$, should lead to the formation of a zigzag type neutral 1-D network (Fig. 1b), and the chelating phenanthroline moiety capable of binding metal cations (Fig. 1a). Owing to its loose coordination requirements and the 60 reversible nature of its interactions with $\mathrm{N}$ bearing ligands such as phenanthroline, $\mathrm{Ag}^{+}$cation was used as the metallic tecton. Finally, for charge neutralisation, rather weakly coordinating $\mathrm{XF}_{6}{ }^{-}(\mathrm{X}=\mathrm{P}, \mathrm{As}, \mathrm{Sb})$ anions were employed. The use of three isostructural anions was made in order to validate ${ }_{65}$ the robustness of the design principle. Thus, by design, the tetra components ensemble should generate a 2-D network (Fig. 1c) resulting from the interconnection of zigzag type neutral 1-D networks by silver cations. It is worth noting that although the connectivity of the 2-D sheets is imposed by the 70 design and combination of tectons $\mathbf{1}^{2+}, \mathbf{2}^{2-}$ and $\mathrm{Ag}^{+}$, the localisation of the anion and possible solvent molecules, which do not behave as tectons since they do not participate in the connectivity of the network, remains indeterministic and thus not predictable.

75

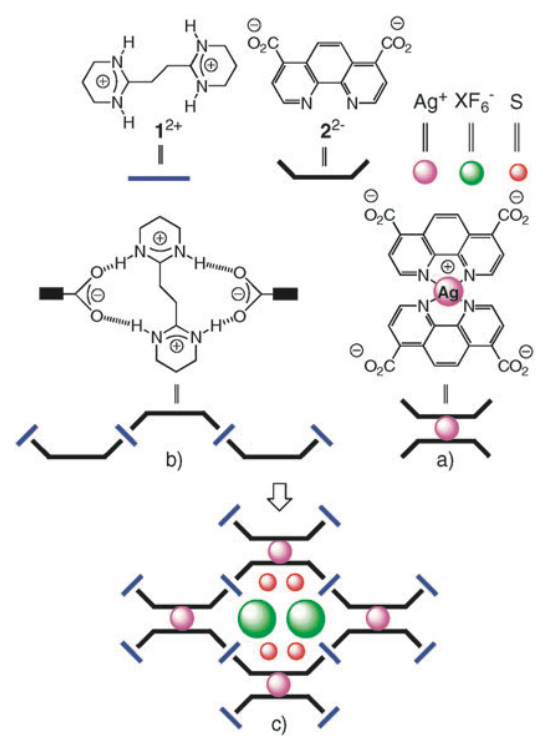

Figure 1: Schematic representation of a portion of the 2-D network based on $\mathbf{1}^{2+}, \mathbf{2}^{2-}, \mathrm{Ag}^{+}, \mathrm{XF}_{6}{ }^{-}(\mathrm{X}=\mathrm{P}, \mathrm{As}, \mathrm{Sb})$ and solvent molecules. The combination of $\mathbf{1}^{2+}$ and $\mathbf{2}^{2-}$ leads to the formation of a neutral H-bonded 1$80 \mathrm{D}$ networks and their interconnection by silver cations generates the 2-D network. 
The solid-state structure of $\mathbf{2}$, studied by X-ray diffraction on single crystal, revealed that compound $\mathbf{2}$ behaves as a zwitterion and forms a 2-D H-bonded network (see ESI for detailed structural description). The combination of $\mathbf{2}$ with $5 \mathrm{AgPF}_{6}$ afforded the neutral $\left[\left(\mathrm{Ag}^{+}-(\mathbf{2 , 2})\right]\right.$ complex (Fig. 2a) for which, as previously reported for phenanthroline ${ }^{14}$, the coordination geometry around the cation is a distorted tetrahedron $\left(\mathrm{d}_{\mathrm{Ag}-\mathrm{N}}=2.279(5) \AA\right.$ and $2.381(5) \AA, \mathrm{NAgN}_{\text {cis }}$ angle in the range of $70.7^{\circ}-152.6^{\circ}$ ) (see ESI for detailed 10 structural description). The complex are interconnected through $\mathrm{OH}^{\cdots} \mathrm{O}$ type $\mathrm{H}$-bonds leading thus to 1-D $\mathrm{H}$ bonded networks.

Compounds $\mathbf{1}$ and $\mathbf{2}$ are a dibase and a diacid respectively. Owing to the difference in their $p \mathrm{Ka}$ values, their mixing 15 should lead to the formation of $\left(\mathbf{1}^{2+}, \mathbf{2}^{2-}\right)$ complex. The solidstate structure of the latter combination was also studied and indeed confirmed the proton transfer (Fig. 2b). As expected, a zigzag type 1-D $\mathrm{H}$ bonded network resulting from the mutual interconnection of $\mathbf{1}^{2+}$ and $\mathbf{2}^{2-}$ through a dihapto mode of $\mathrm{H}$ 20 bonding is observed (see ESI for detailed structural description).
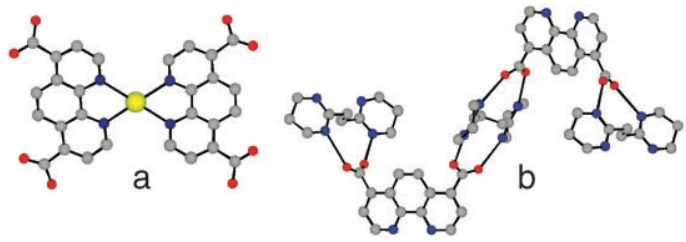

Figure 2: Coordination node resulting from the binding of $\mathrm{Ag}^{+}$by two $\mathbf{2}^{2-}$ 25 in $\left[\left(\mathrm{Ag}^{+}-(\mathbf{2 , 2})\right]\right.$ (a) ; formation of the dihapto $\mathrm{H}$-bonded recognition pattern between $\mathbf{1}^{2+}$ and $\mathbf{2}^{2-}$ in $\left(\mathbf{1}^{2+}, \mathbf{2}^{2-}\right)$ (b). $\mathrm{H}$ atoms are not presented for sake of clarity. For bond distances and angles see text and ESI.

The combination of the individual components $\mathbf{1}, \mathbf{2}$ and $\mathrm{AgXF}_{6}(\mathrm{X}=\mathrm{P}, \mathrm{As}, \mathrm{Sb})$, leads, under self assembly conditions 30 (see ESI), to slightly yellowish crystals suitable for X-ray diffraction on single crystals. For all three silver salts, their crystal structure was investigated by both X-Ray diffraction on single crystal and on powder (see ESI). Owing to the observed isostructurality between them, only the structure of 35 the $\mathrm{Sb}$ salt will be discussed in detail here. In all three cases, the crystal was composed of $\mathbf{1}^{2+}$ and $2^{2-}, \mathrm{Ag}^{+}$cation and $\mathrm{XF}_{6}{ }^{-}$ anion $(\mathrm{X}=\mathrm{P}, \mathrm{As}, \mathrm{Sb})$ and $\mathrm{MeOH}$ solvent molecules. The latter was found to be disordered over two positions with occupancy of $50 \%$. The crystal may be described as resulting

40 from the packing of 2-D networks composed of cationic and anionic tectons $\mathbf{1}^{2+}$ and $\mathbf{2}^{2-}$ respectively and $\mathrm{Ag}^{+}$cations offering empty spaces occupied by anions and solvent molecules (Fig. 3). As expected by the design and choice of tectons, the 2-D network is based on two different assembling 45 nodes i.e. charge-assisted $\mathrm{H}$-bonds and coordination bond. Thus, the overall architecture may be described as parallel 1D H-bonded networks interconnected by silver cations. Les paramètres nécessaires sont manquants ou erronés.

For the charge-assisted $\mathrm{H}$-bonded node, the recognition of the 50 carboxylate moiety of $\mathbf{2}^{2-}$ by $\mathbf{1}^{2+}$ takes place, as expected and observed for the combination of $\mathbf{1}^{2+}$ with $\mathbf{2}^{2-}$ (Fig. 2b), through a dihapto mode of $\mathrm{H}$-bonding with $\mathrm{N} \cdots \mathrm{O}$ distances in the range of $2.742(12)$ to $2.752(13) \AA$. For the cationic tecton $\mathbf{1}^{2+}$, the two amidinium cycles $\left(\mathrm{d}_{\mathrm{C}=\mathrm{N}}=1.301(13)\right.$ and $1.319(15) \AA$, ${ }_{55} \mathrm{NCN}$ angle of $\left.123.9^{\circ}(13)\right)$ adopting a half-chair conformation are connected by a fully extended ethylene spacer (CCCC dihedral angle of $\left.180^{\circ}\right)$. For $2^{2-}$, the carboxylate moieties $\left(\mathrm{d}_{\mathrm{C}-\mathrm{O}}\right.$ $=1.226(13)$ and $1.250(14) \AA)$ are not coplanar with the phenanthroline group but tilted (OCCC dihedral angles of $c a$ ${ }_{60} 37^{\circ}$ and $+38^{\circ}$ ) leading thus to the formation of a puckered sheet. For the structures formed in the presence of $\mathrm{PF}_{6}{ }^{-}$and $\mathrm{AsF}_{6}{ }^{-}$anions, almost the same metrics are observed.

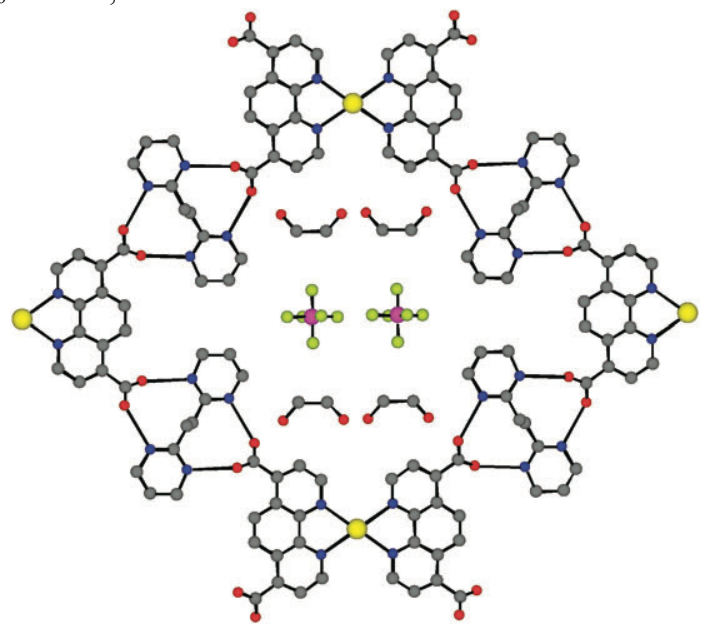

${ }_{65}$ Figure 3: A portion of the solid-state structure of $\left(\mathbf{1}^{2+}, \mathbf{2}^{2-}, \mathrm{Ag}^{+}, \mathrm{SbF}_{6}{ }^{-}\right)$ showing the formation of the 2-D network and the encapsulation of anions and solvent molecules. $\mathrm{H}$ atoms are not presented for sake of clarity. For bond distances and angles see text.

For the coordination node (Fig. 3), as observed for $\left[\left(\mathrm{Ag}^{+}-\left(\mathbf{2}, \mathbf{2}^{-}\right.\right.\right.$ $70)$ ] complex (Fig. 2a), the silver cation is surrounded by two anionic units $\mathbf{2}^{2-}$ and its coordination sphere is composed of four $\mathrm{N}$ atoms $\left(\mathrm{d}_{\mathrm{Ag}-\mathrm{N}}=2.363(7) \AA\right)$. In marked contrast with $\left[\left(\mathrm{Ag}^{+}-\left(\mathbf{2}, \mathbf{2}^{-}\right)\right]\right.$complex for which the coordination geometry around the cation is a distorted tetrahedron, here, a deformed 75 square geometry is observed $\left(\mathrm{NAgN}_{\text {cis }}\right.$ and $\mathrm{NAgN}_{\text {trans }}$ angles of $69.7(4)^{\circ}, 110.3(4)^{\circ}$ and $180.0^{\circ}$ respectively).

The purity of the crystalline phase was established by PXRD (Fig. 4), which revealed a single set of diffraction peaks implying a single polycrystalline phase.

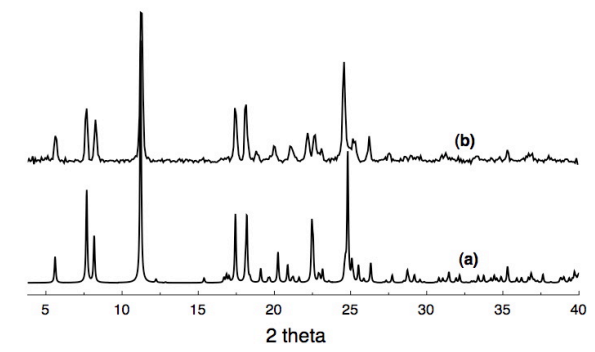

Figure 4: Comparison of the simulated (a) and recorded (b) PXRD patterns for $\left(\mathbf{1}^{2+}, \mathbf{2}^{2-}, \mathrm{Ag}^{+}, \mathrm{SbF}_{6}{ }^{-}\right)$showing the purity of the phase.

The thermal stability of the crystalline materials was investigated by TGA measurements which revealed the 85 complete loss of $\mathrm{MeOH}$ molecules at $c a 80{ }^{\circ} \mathrm{C}$ prior to decomposition which appears at $c a 240{ }^{\circ} \mathrm{C}$.

In the area of crystal engineering, proper and quantitative evaluation of energetic parameters guiding the formation of 
the final crystalline architecture is crucial. ${ }^{15}$ An estimation of the contribution of different recognition events and thus assembling nodes may be obtained using the PACHA type analysis based on electrostatic interactions using the partial 5 charge approach. ${ }^{16}$ Such analysis was carried out for all three crystalline structures reported here (for methodology and detailed analysis see ESI). The calculation revealed that the average contribution of the individual coordination node (Fig. 1a and $1 \mathrm{~b}$ ) was $c a 40 \%$ whereas the contribution of the 10 charge-assisted $\mathrm{H}$-bonded pattern leading to the formation of 1-D networks (rods) was $60 \%$ (Fig. 5). The fact that the coordination event was less energetic than the H-bonding phenomena is due to the presence of strong electrostatic interactions (charge-assisted H-bonding). Interestingly for the 15 formation of 2-D network (sheet composed of $\mathbf{1}^{2+}, \mathbf{2}^{2-}, \mathrm{Ag}^{+}$ and $\mathrm{XF}_{6}{ }^{-}$) based on both types of assembling nodes (Fig. 1c, Fig. 3), again the contribution of the coordination event (43 \%) was lower than the one H-bonded pattern (57\%). Finally, for the entire crystal, in addition to contributions of 20 coordination ( $c a 44 \%$ ) and H-bonding ( $c a 49 \%$ ), $\mathrm{MeOH}$ molecules participate, through the formation of $\mathrm{H}$-bonds with carboxylate moieties of $\mathbf{2}^{2-}$, to the cohesion of the crystal by ca $6 \%$. These calculated energetic contributions clearly demonstrate that, as expected by the design and combination 25 of tectons $\mathbf{1}^{2+}, \mathbf{2}^{2-}$ and $\mathrm{Ag}^{+}$, the formation of the 2-D networks is mainly dominated by molecular recognition events.

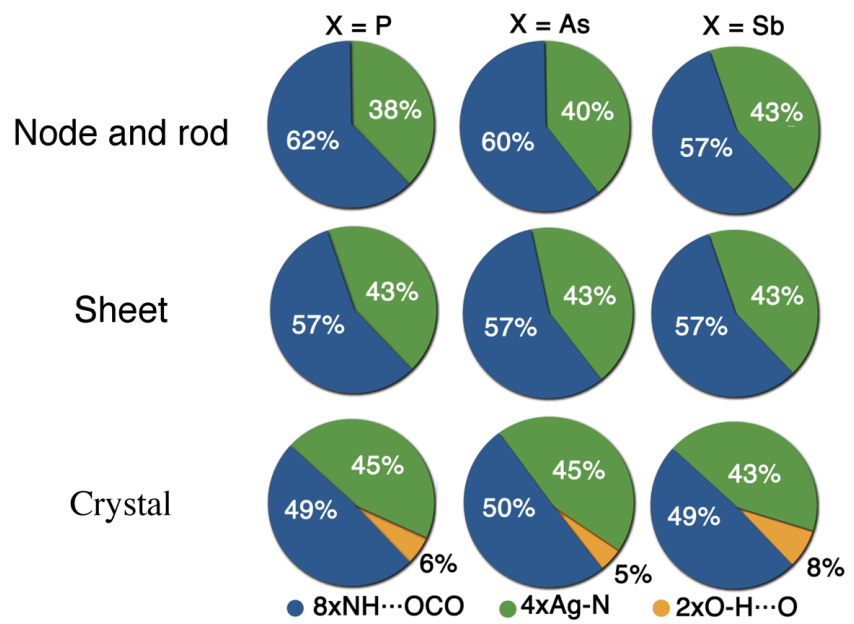

30 Figure 5: calculated contributions (in percentage of total energy) of different recognition and packing events For detail see text and supplementary part.

In conclusion, in order to demonstrate the viability of the crystal engineering approach, using a combination of charge35 assisted $\mathrm{H}$ - and coordination bonds, a tetra component system composed of a dicationic and a dianionic organic tectons, $\mathrm{Ag}^{+}$ cation and $\mathrm{XF}_{6}{ }^{-}(\mathrm{X}=\mathrm{P}, \mathrm{As}, \mathrm{Sb})$ anion was designed to generate 2-D networks. The system behaved precisely according to the plan and the calculated energetic 40 contributions confirm that the formation of the 2-D network is mainly dominated by the two recognition events. Currently, we are exploring the possibility of enhancing both the number of components and the number and type of assembling nodes.
${ }_{45}$ We thank the Université de Strasbourg, the International Center for Research in Frontiers of Chemistry (FRC), the Institut Universitaire de France, the Ministry of Education and Research, the CNRS and Marie Curie EST Actions FUMASSEC Network (Contrat $N^{\circ}$ MEST-CT-2005-020992) ${ }_{50}$ for financial support.

\section{Notes and references}

${ }^{a}$ Laboratoire de Chimie de Coordination Organique, ${ }^{b}$ Laboratoire de Chimie Moléculaire de L'État Solide, UMR CNRS 7140, Université de ${ }_{55}$ Strasbourg, Institut Le Bel, 4, rue Blaise Pascal, F-67000 Strasbourg, France

Electronic supplementary information (ESI) available: new synthesis of 1, cristallographic data (including CCDC numbers) for all reported structures, detailed structural analysis of $\mathbf{2}$, of $\left[\left(\mathrm{Ag}^{+}-\left(\mathbf{2}, \mathbf{2}^{-}\right)\right]\right.$complex and of $60\left(\mathbf{1}^{2+}, \mathbf{2}^{2-}\right)$ complex, procedures and characterisations (PRXD patterns, IR) for $\left(\mathbf{1}^{2+}, \mathbf{2}^{2-}, \mathrm{Ag}^{+}, \mathrm{XF}_{6}, \mathrm{X}=\mathrm{P}, \mathrm{As}, \mathrm{Sb}\right)$ and detailed energy analysis by the PACHA sofware.

1 a) G. M. Schmidt, J. Pure Appl. Chem. 1971, 27, 647; b) G. D. 65 Desiraju, Crystal Engineering: The Design of Organic Solids; Elsevier: New York, 1989; c) M. C. Etter, Acc. Chem. Res., 1990, 23, 120.

2 a) J. Maddox, Nature, 1988, 335, 201; b) A. Gavezzotti, Acc. Chem. Res., 1994, 27, 309; c) J. D. Dunitz, Chem. Comm, 2003, 545.

70 3) a) M. Simard, D. Su, J. D. Wuest, J. Am. Chem. Soc., 1991, 113, 4696; b) S. Mann, Nature, 1993, 365, 499; c) M. W. Hosseini, Acc. Chem. Res., 2005, 38, 313.

4 a) F. W. Fowler, J. W. Lauher, J. Am. Chem. Soc., 1993, 115, 5991; b) M. W. Hosseini, CrystEngComm, 2004, 6, 318.

755 M. W. Hosseini, Chem. Commun., 2005, 582.

6 J.-M. Lehn, Supramolecular Chemistry, Concepts and Perspectives, VCH, Weinheim, 1995.

7 M. W. Hosseini, A. De Cian, Chem. Commun. 1998, 727.

8 a) C. B. Aakeröy, K. R. Seddon, Chem. Soc. Rev. 1993, 22, 397; b) S. Subramanian, M. J. Zaworotko, Coord. Chem. Rev. 1994, 137, 357.

9 a) S. R. Batten and R. Robson, Angew. Chem. Int. Ed., 1998, 37, 1460 ; b) A. J. Blake, N. R. Champness, P. Hubberstey, W.-S. Li, M. A. Withersby and M. Schröder, Coord. Chem. Rev.,1999, 193, 117.

10 a) C. B. Aakeröy, A. M. Beatty and B. A. Helfrich, J. Chem. Soc. 85 Dalton Trans., 1998, 1943; b) J. C. MacDonald, P. C. Dorrestein, M. M. Pilley, M. M. Foote, J. L. Lundburg, R. W. Henning, A. J. Schultz, J. L. Manson J. Am. Chem. Soc. 2000, 122, 11692; c) M. V. Yigit, K. Biyikli, B. Moulton, J. C. MacDonald, Crystal Growth \& Design, 2006, 6, 63 ; d) B. Moulton and M. J. Zaworotko, Chem. Rev., 2001, 101, 1629; e) A. M. Beatty, Coord. Chem. Rev., 2003, 246, 131; f) L. Brammer, Chem. Soc. Rev., 2004, 33, 476; g) D. Braga, S. L. Giaffreda, F. Grepioni, L. Maini and M. Polito, Coord. Chem. Rev., 2006, 250, 1267 ; h) J. Pansanel, A. Jouaiti, S. Ferlay, M. W. Hosseini, J.-M. Planeix, N. Kyritsakas, New J. Chem., 2006, 1, 71 ; i) Z. Lin, Y. Li, A. M. Z. Slawin, R. E. Morris Dalton Trans., 2008,3989 ; j) S. A. Baudron, D. Salazar-Mendoza, M. W. Hosseini, CrystEngCom., 2009, DOI: 10.10134/b901167f.

11 a) G. Brand, M; W. Hosseini, R. Ruppert, A. De Cian, J. Fischer, N. Kyritsakas, New J. Chem., 1995, 19, 9; b) M. W. Hosseini, R.

100 Ruppert, P. Schaeffer, A. De Cian, N. Kyritsakas, J. Fischer, Chem. Commun. 1994., 2135 ; c) O. Félix, M. W. Hosseini, A. De Cian, J. Fischer, New. J. Chem., 1998, 22, 1389.

12 M. W. Hosseini, Coord. Chem. Rev., 2003, 240, 157.

13 K. T. Holman, A. M. Pivovar, J. A. Swift, M. D. Ward, Acc. Chem. Res., 2001, 34, 107.

14 M. Leschke, G. Rheinwald, H. Lang, Z. Anorg. Allg. Chem, 2002, 628, 2470.

15 M. Henry, M. W. Hosseini, New J. Chem., 2004, 28, 897.

16 a) M. Henry, CHEMPHYSCHEM, 2002, 3, 561; b) M. Henry, in 110 "Advances in Quantum Chemical Bonding Structures", M.V. Putz Ed., Transworld Research Network, Kerala (2008) p. 153. 